\title{
Volatile Flavor Compounds in the Leaves of Fifteen Taxa of Korean Native Chrysanthemum Species
}

\author{
Su Jeong Kim ${ }^{1 *}$, Tae Joung $\mathrm{Ha}^{2}$, Jongyun $\mathrm{Kim}^{3}$, Jung Hwan Nam${ }^{1}$, Dong Lim Yoo ${ }^{1}$, Jong Taek Suh ${ }^{1}$, and \\ Ki Sun Kim ${ }^{4}$ \\ ${ }^{1}$ Highland Agriculture Research Center, National Institute of Crop Science, Rural Development Administration, Pyeongchang 232-955, Korea \\ ${ }^{2} R \& D$ Performance Evaluation \& Management Division, Research Policy Bureau, Rural Development Administration, Jeonju 560-500, Korea \\ ${ }^{3}$ Division of Horticulture and Landscape Architecture, Pai Chai University, Daejeon 302-735, Korea \\ ${ }^{4}$ Department of Plant Science, Seoul National University, Seoul 151-921, Korea
}

\begin{abstract}
This study was conducted to compare the volatile flavor compounds found in the leaves of 15 taxa of Korean native Chrysanthemum species. The volatile flavor compounds from the taxa were collected using a simultaneous steam distillation and extraction technique and were analyzed using gas chromatography/mass selective detector (GC/MSD). A total of 45 volatile flavor compounds were identified with six functional groups: 14 alcohols, 4 ketones, 19 hydrocarbons, 5 esters, 2 acids, and 1 aldehyde. The main functional group in 15 taxa of Chrysanthemum species was alcohols, accounting for $28.7 \%$ of volatile flavor compounds, followed by ketones (21.2\%) and hydrocarbons (13.2\%). Camphor, which is known for its antimicrobial properties, was the most abundant volatile compound (30\%) in C. zawadskii ssp. latilobum and var. leiophyllum. In particular, C. indicum subspecies and $C$. boreale contained $\alpha$-thujone, which has outstanding anti-bacterial, anti-cancer, anti-inflammatory, anti-ulcer, and anti-diabetic efficacies. $C$. indicum var. albescens could be used in perfumes, since it showed 21 times more camphene than C. indicum. In addition, $C$. indicum var. acuta contained a fairly high content of 1,8-cineole, which has an inhibitory effect on mutagenesis. $C$. lineare contained only pentadecanoic acid compounds, whereas other taxa hexadecanoic acids. Overall, the Korean native Chrysanthemum species had considerable variation in volatile flavor compounds in their leaves. This study provides a good indication of specific potential use for various applications.
\end{abstract}

Additional key words: borneol, camphor, GC/MSD, ketone, native plant

\section{Introduction}

Korean native Chrysanthemum species are perennial Asteraceae plants that have been used as natural medicine or food as well as an ornamental since the ancient times (Choi, 1992). Since Korean native Chrysanthemum species contain a lot of terpene compounds, they have been used as ingredients in cosmetics (Kim et al., 1995; Matsuda et al., 2002), foods (Ko and Jeon, 2003), and folk medicines (Kim et al., 1998; Nam and Yang, 1995) for a long time. Recently, the antioxidant activation and anti-inflammatory effects of the flavor compounds in Korean native Chrysanthemum species have been reported (Bae and Lee, 2008; Sung et al., 2007; Yoon and Cho, 2007), and food processing studies with its healthful benefits have been conducted, such as utilizing Chrysanthemum species for cookie powder (Bae et al., 2009) and rice cake powder (Park and Shin, 1998; Park et al., 2000). Chrysanthemum species also have been proposed as a potential ingredient for herbal cosmetics involving the effects of tyrosinase inhibitory activity associated

\footnotetext{
*Comesponding author: sjkim30@korea.kr

※ Received 22 October 2013; Revised 10 April 2014; Accepted 29 April 2014. This work was carried out with the support of "Cooperative Research Program for Agriculture Science \& Technology Development (Project No. PJ00646008 and No. PJ00876405)" Rural Development Administration, Republic of Korea. The authors would like to thank Dr. Jeong-Hun Lee and Ms. Mi Yeong Park for their assistance with Herbaria vouchers specimen production. Our special thanks are also extended to Dr. Manjulata for the English manuscript of the study. 
with anti-oxidant activation, whitening, and moisturizing effects (Bae et al., 2009; Sung et al., 2007; Yoon and Cho, 2007).

There are three main native Chrysanthemum species in Korea: $C$. zawadskii, $C$. indicum, and $C$. boreale, with each species having several subspecies (Lee, 2006). In particular, C. zawadskii has been used for treating various women's diseases, menstrual irregularity, cold stomach, indigestion, pneumonia, bronchitis, urinary disorders, and neurodegenerative diseases (Lee et al., 2008). C. zawadskii also has a great potential as a pharmacological ingredient in shampoo products due to its high anti-bacterial activity against dandruff (Lee and Lee, 2007). Previous research indicated that $C$. indicum also contains several healthful volatile flavor compounds and various vitamins, which benefit blood flow in long-term use, refresh the body, help digestion, alleviate fever and headaches, lower blood pressure, and offer efficacy such as inhibitory effects against tuberculosis and various viruses (Shin et al., 2004; Sung et al., 2007). C. indicum had been used to make chrysanthemum wine for celebrations during the Chosun Dynasty (AD 1392 to 1897). C. indicum has also been used as a medicinal wine for patients with hypertension (Choi, 1992) and a natural flavoring ingredient in traditional foods (Bae et al., 2009) in Korea. Dried C. indicum was also used to make tea or added to foods (Yoon and Cho, 2007). The benefits of $C$. boreale were reported to be associated with sedation of the central nervous system, hypotensive effects (Nam et al., 1997), and anti-microbial effects (Cha et al., 2000; Jang et al., 1999; Nam and Yang, 1995). Additional benefits include reductase inhibitory effects of enzyme aldose (Shin et al., 1995), related to anti-cancer (Nam et al., 1997), and diabetic complications (Shin et al., 1995).

With the increasing interest and use of Korean native Chrysanthemum species as pharmacological ingredients, cosmetics ingredients, and in health food, several studies on volatile flavor compounds of Chrysanthemum species have been conducted. Byun et al. (2006) reported that anti-oxidant compounds such as flavonoids, terpenoids, and phenolic compounds were the main functional compounds of the Korean native Chrysanthemum species. Through previous research, it was reported that the main compounds of volatile flavors derived from $C$. indicum and $C$. boreale were 1,8-cineole, germacrene-D, camphor, $\alpha$-pinene, and camphene, whereas those from $C$. zawadskii ssp. latilobum were mainly terpenoids such as camphene and ocimene (Hong, 2002; Jiang et al., 2005; Kim, 1997; Wang and Yang, 2006; Wang et al., 2008). However, despite these studies, species-specific volatile flavor compounds found in Korean native Chrysanthemum species are not clearly compared yet.

This study aims to provide a comparison of volatile flavor compounds among 15 taxa of Korean native Chrysanthemum species by analyzing and comparing the species-specific volatile flavor compounds. Results of the study provide clear species-specific volatile flavor compound resource, which could be used as basic data for the germplasms and potential ingredient for functional foods, medicines, and cosmetics.

\section{Materials and Methods}

\section{Plant Materials}

Fifteen taxa of Korean native Chrysanthemum species were collected from different regions, and grown in greenhouse at Highland Agriculture Research Center $\left(37^{\circ} 40^{\prime} \mathrm{N}\right.$, $128^{\circ} 43^{\prime} \mathrm{E}$, altitute $722 \mathrm{~m}$ ), Rural Development Administration in Pyeongchang, Korea since 2010 (Table 1). From July 12-14, 2011, $20 \mathrm{~g}$ of leaves from each Chrysanthemum species were collected. The leaves were stored in $-70^{\circ} \mathrm{C}$ deep freezer and freeze-dried using freezing dryer (FDT12012, Operon Co., Gimpo, Korea).

\section{Extraction of Volatile Flavor Compounds}

To extract the volatile flavor compounds, simultaneous steam distillation (SDE; Likens \& Nickerson type) were done following the extraction method of Schultz et al. (1977). Two grams of freeze-dried leaf sample and 500 $\mathrm{mL}$ of distilled water were added to one of the flasks, and heated-reflux was performed for $2 \mathrm{~h}$ on a $100^{\circ} \mathrm{C}$ heating mantle. Meanwhile, the essential oils were extracted by adding $50 \mathrm{~mL}$ of $\mathrm{n}$-pentane:diethyl ether mixture $11: 1=$ $\mathrm{v}: \mathrm{v}$ ) in the other flask and heated-refluxing to $40^{\circ} \mathrm{C}$. The extracted volatile flavor compounds were dehydrated using anhydrous sodium sulfate $\left(\mathrm{Na}_{2} \mathrm{SO}_{4}\right)$. Afterwards, they were filtered using filter paper (No. 1, Whatman Limited, Maidstonekent, UK), and concentrated using 99.9\% nitrogen gas. Finally, the concentrated compounds were dissolved in 0.2 $\mathrm{mL}$ of diethyl ether and analyzed using gas chromatography/ mass selective detector (GC/MSD) as below.

\section{Analysis of Volatile Flavor Compounds}

The extracted volatile flavor compounds were analyzed and identified using GC/MSD as described in Table 2. About $1.0 \mu \mathrm{L}$ of the extracted volatile flavor compounds was injected into GC (Agilent 7890A, Agilent Co., Wilmington, DE, USA) equipped with HP-5MS capillary column (30 m 
Table 1. List of 15 taxa of Korean native Chrysanthemum species used in this study.

\begin{tabular}{|c|c|c|}
\hline Scientific name & $\begin{array}{c}\text { KMRH }^{\mathrm{z}} \\
\text { voucher }\end{array}$ & Cites (Natural habitats) \\
\hline C. zawadskii Herbich ssp. acutilobum (DC.) Kitagawa & MPS003031 & Mt. Yumyeong, Gyeonggi-do, Korea \\
\hline C. zawadskii Herbich ssp. acutilobum (DC.) Kitagawa var. alpinum (Nak.) Y. Lee & MPS003033 & Mt. Baekdu, Hamgyeongbook-do, Korea \\
\hline C. zawadskii Herbich ssp. lucidum (NAK.) Y. Lee & MPS003034 & Ullung, Gyeongsangbook-do, Korea \\
\hline C. zawadskii Herbich ssp. yezoense (Maekawa.) Y. Lee & MPS003039 & Goheung, Jeollanam-do, Korea \\
\hline C. zawadskii Herbich ssp. latilobum (Maxim.) Kitagawa & MPS003041 & Wando, Jeollanam-do, Korea \\
\hline C. zawadskii Herbich ssp. latilobum (Maxim.) Kitagawa var. leiophyllum (Nak.) Y. Lee & MPS003043 & Gangneung, Gangwon-do, Korea \\
\hline C. indicum Linné & MPS003044 & Anmyeondo, Chungcheongnam-do, Korea \\
\hline C. lineare Matsumura & MPS003050 & Mt. Chilbo, Gyeonggi-do, Korea \\
\hline C. makinoi Matsumura et Nakai & MPS003051 & Daegu, Korea \\
\hline
\end{tabular}

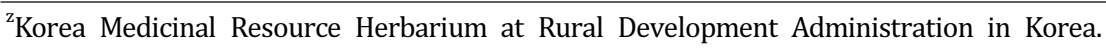

Table 2. Analytical condition of GC-MS for the identification of volatile flavor compounds in 15 taxa of Korean native Chrysanthemum species.

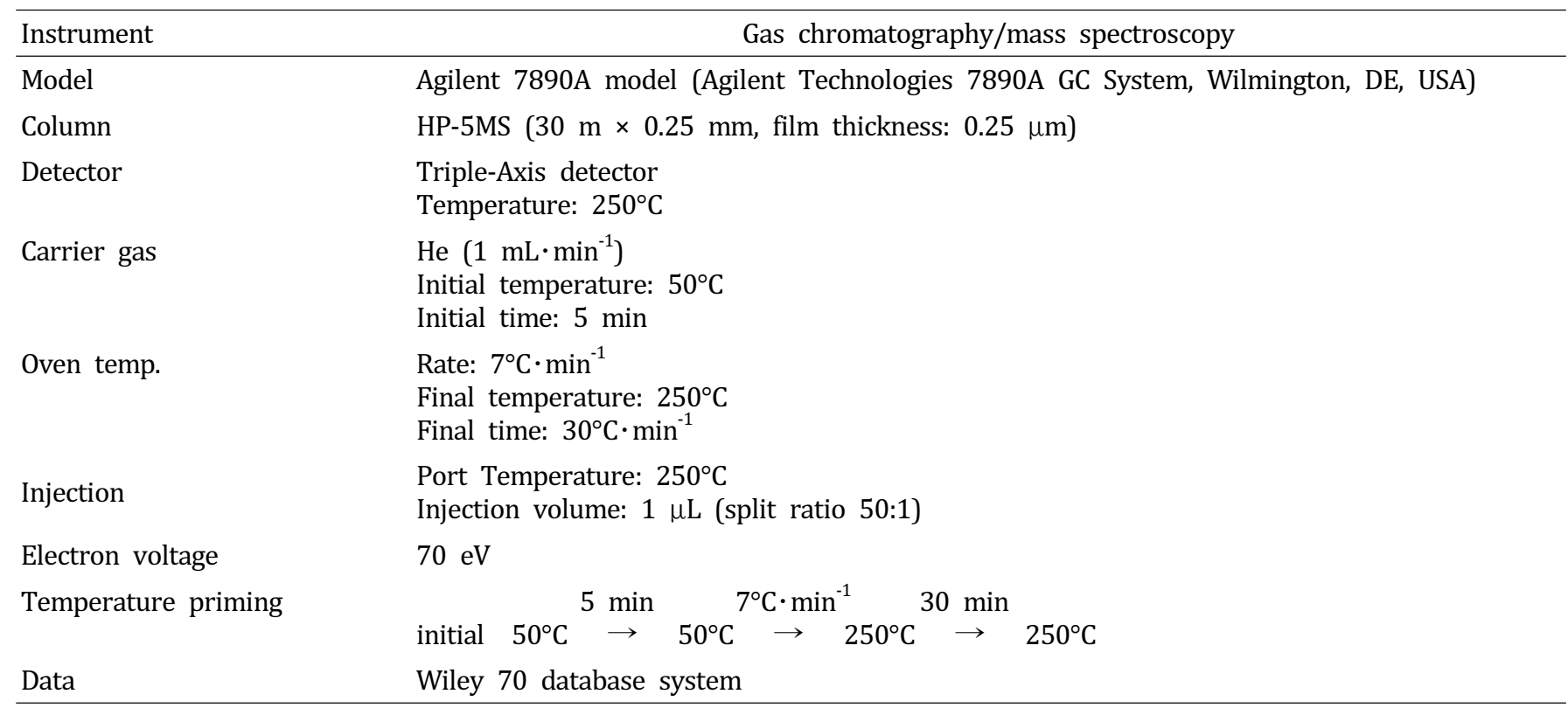

$\times 0.25 \mathrm{~mm}$ i.d., $0.25 \mu \mathrm{m}$ film thickness) and was analyzed by split mode (split ratio $=50: 1$ ). As for GC analysis conditions, the inlet and detector temperatures were maintained at $250^{\circ} \mathrm{C}$, and the helium carrier gas flow rate at $1.0 \mathrm{~mL}$ per minute. The oven temperature was kept at $50^{\circ} \mathrm{C}$ for $5 \mathrm{~min}$, raised by $7^{\circ} \mathrm{C}$ per min, and then maintained for $30 \mathrm{~min}$ at $250^{\circ} \mathrm{C}$. For GC/MSD conditions, the electron ionization energy was $70 \mathrm{eV}$, the ion source temperature was $250^{\circ} \mathrm{C}$, and the mass range was 20-400 a.m.u. Regarding verification of the compounds, the mass spectrum obtained using GC/MSD was compared with Wiley 275L database system (Wiley 70, Agilent Co., Wilmington, DE, USA) and mass 
spectral data from the previous literature (Kondjoyan and Berdague, 1996) for the identification. $\mathrm{C}_{5}-\mathrm{C}_{20}$ of alkane (Aldrich Chemical Co., Milwaukee, WI, USA) were used as reference flavor compound materials and expressed in terms of relative peak area (\%).

\section{Statistical Analysis}

In order to compare the volatile flavor compounds among Chrysanthemum species, analysis of variance (ANOVA) was used to compare the means $(n=4)$ of the peak area from GC/MSD using SAS program (SAS institute, ver. 9.2, Cary, NC, USA). Levels of significance were calculated using ANOVA test at $p \leq 0.05,0.01$, and 0.001 . Values of $p$ $\leq 0.05$ were considered to be statistically significant.

\section{Results and Discussion}

\section{Volatile Flavor Compounds Found in Korean native Chrysanthemum Species}

Identification of the volatile flavor compounds in 15 taxa of Korean native Chrysanthemum species was accomplished by comparing the mass spectra of their components with the Wiley database, and their GC retention time with GC/MSD spectral data (data not shown).

The flavor compounds of 15 taxa of Chrysanthemum species are constituted of six large functional groups, such as alcohols, ketones, hydrocarbons, esters, acids, and aldehyde. On the average, alcohols were the highest flavor compound group (28.7\%) in 15 taxa of Chrysanthemum species, followed by ketones (21.2\%), and hydrocarbons $(13.2 \%)$ based on peak area (Table 3). Three functional groups consisted of $63.1 \%$ of the total flavor compounds in 15 taxa of Chrysanthemum species. These compositions were dependent on the taxa; alcohols were the most abundant flavor compounds in 8 taxa, and ketones were the most abundant in the other 7 taxa. All the taxa showed negligible amount $(<1 \%)$ or no aldehyde compound. Although most taxa contained little $(<2 \%)$ to none acid compound, $C$. indicum and $C$. lineare contained particularly high acid contents at $4.95 \%$ and $10.88 \%$ of peak area, respectively. Esters consisted of $0.0-11.3 \%$ of peak area depending on the species, and $C$. zawadskii ssp. acutilobum had the highest esters contents among the taxa.

Comparison of the flavor compounds in 15 taxa of Chrysanthemum species is shown in Table 4. GC chromatogram showed 45 volatile flavor compounds from 12 to 32 volatile flavors each depending on taxa. The six flavor compounds, including sabinene, cis-chrysanthenol, borneol, $m$-thymol, chrysanthenone, and camphor showed the most significant differences among the taxa $(p \leq 0.001)$. Sabinene was detected at a significant amount only in $C$. zawadskii subspecies and C. makinoi. cis-Chrysanthenol was detected only in four taxa of $C$. zawadskii subspecies such as ssp. naktongense, yezoense, latilobum, and latilobum var. leiophyllum Significant differences $(p \leq 0.01)$ in $\gamma$-terpinene, 1-octen3-ol, linalool, $\alpha$-terpineol, hinesol, and trans-chrysanthenyl acetate were found among the taxa. In particular, $\gamma$-terpinene, 1-octen-3-ol and $\alpha$-terpineol were detected only in $C$. zawadskii subspecies and $C$. makinoi, while hinesol was detected only in $C$. indicum subspecies and $C$. boreale. To investigate the differences in flavor compounds among 15 taxa of Chrysanthemum species, we compared the flavor compounds within the six functional categories of the compounds below.

Table 3. Variation in the functional group of volatile flavor compounds among 15 taxa of Korean native Chrysanthemum species in greenhouse of highland area.

\begin{tabular}{|c|c|c|c|c|c|c|c|c|c|c|c|c|c|c|c|c|}
\hline \multirow{2}{*}{ Functional group } & \multicolumn{15}{|c|}{ Peak area (\%) of volatile flavor compounds in Chrysanthemum species ${ }^{z}$} & \multirow{2}{*}{ Mean } \\
\hline & $\mathrm{A}$ & B & $\mathrm{C}$ & D & $\mathrm{E}$ & $\mathrm{F}$ & $\mathrm{G}$ & $\mathrm{H}$ & I & $\mathrm{J}$ & $\mathrm{K}$ & $\mathrm{L}$ & M & $\mathrm{N}$ & 0 & \\
\hline Alcohols & 24.3 & 22.8 & 34.4 & 35.9 & 31.3 & 27.4 & 25.8 & 28.5 & 26.2 & 24.2 & 43.0 & 20.6 & 41.3 & 19.7 & 25.0 & 28.7 \\
\hline Hydrocarbons & 9.4 & 12.4 & 13.8 & 21.3 & 15.4 & 18.2 & 18.4 & 11.1 & 11.2 & 11.5 & 18.9 & 15.5 & 9.2 & 3.3 & 8.1 & 13.2 \\
\hline Esters & 11.3 & 9.5 & 3.8 & 4.2 & 4.2 & 7.0 & 2.0 & 5.3 & 2.9 & 0.0 & 0.6 & 3.5 & 0.3 & 2.2 & 0.2 & 3.8 \\
\hline Aldehyde & 0.1 & 0.1 & 0.2 & 0.0 & 0.2 & 0.3 & 0.2 & 0.8 & 0.6 & 0.0 & 0.4 & 0.3 & 0.3 & 0.0 & 0.1 & 0.3 \\
\hline
\end{tabular}

${ }^{\mathrm{z}}$ A, C. zawadskii ssp. acutilobum; B, C. zawadskii ssp. acutilobum var. tenuisectum; C, C. zawadskii ssp. acutilobum var. alpinum; D, C. zawadskii ssp. lucidum; E, C. zawadskii ssp. coreanum; F, C. zawadskii ssp. naktongense; G, C. zawadskii ssp. yezoense; H, C. zawadskii ssp. latilobum; I, C. zawadskii ssp. latilobum var. leiophyllum; J, C. indicum; K, C. indicum var. albescens; L, C. indicum var. acuta; $\mathrm{M}$, C. boreale; N, C. lineare; 0, C. makinoi. 
Table 4. Components of the volatile flavor compounds obtained from 15 taxa of Korean native Chrysanthemum species in greenhouse at highland areas.

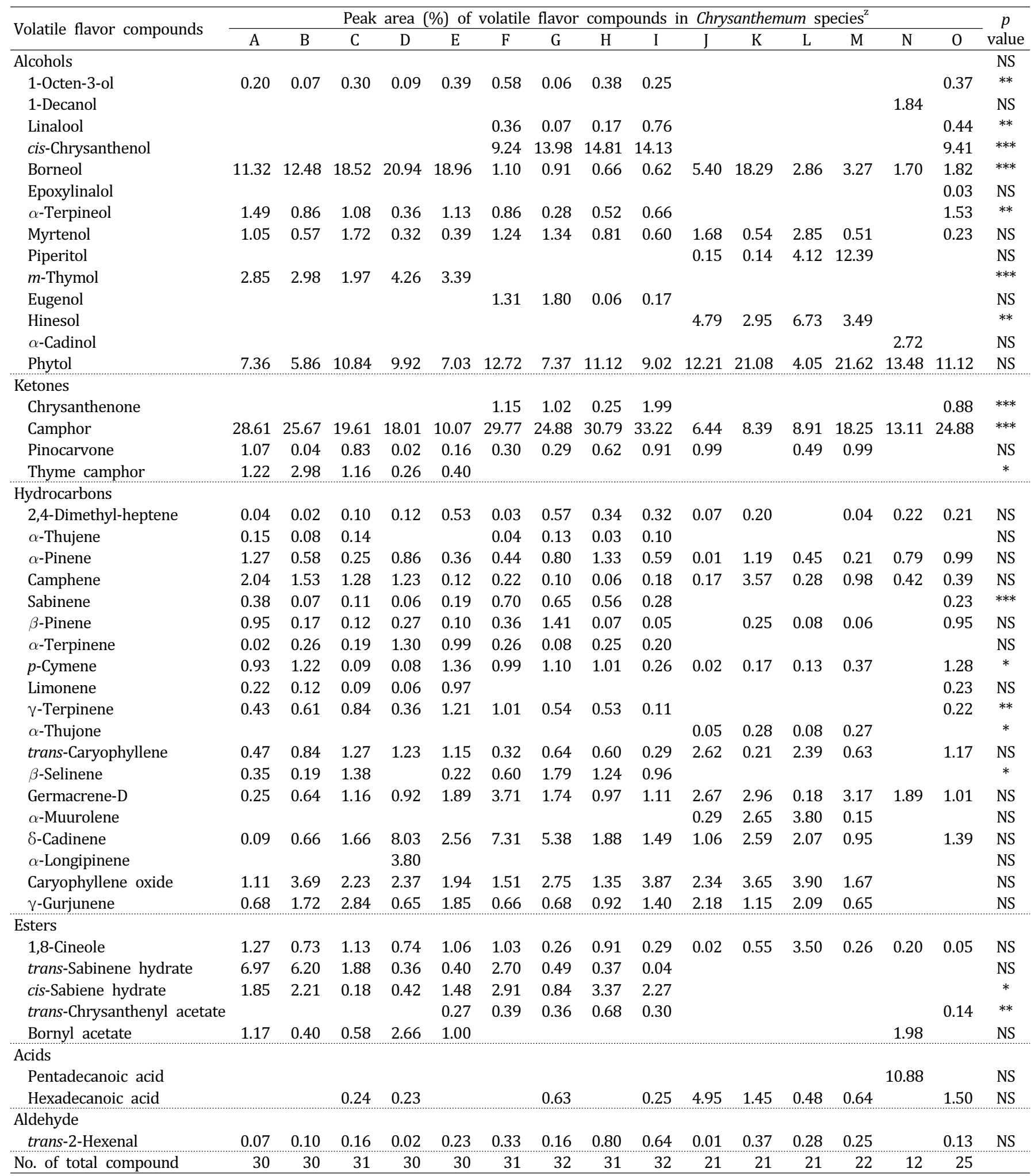

${ }^{\mathrm{z}}$ For species name, refer to Table 3.

$\mathrm{NS}^{, * * *+* * * * *}$ Non-significant or significant at $p \leq 0.05,0.01$, or 0.001 , respectively within the same row. 


\section{Alcohols}

Alcohols were the most abundant flavor compounds (19.7-43.0\% of peak area) in 8 taxa of Chrysanthemum species, which include three subspecies of $C$. zawadskii, and $C$. indicum subspecies, $C$. boreale, and $C$. lineare (Table 4). Although a total of 14 alcohols were detected from all taxa, their contents were different depending on the taxa. Chang and Kim (2009) reported that 12 alcohols were detected in flower of $C$. indicum, including 1,8-cineole, chrysanthenol, isopinocarveol, borneol, terpinen-4-ol, endoborneol, carveol, eugenol, spathulenol, cedrol, vulgarol B, and $\alpha$-bisabolol. Choi et al. (2006) reported 11 alcohols in flower of $C$. boreale, which was more than the number of alcohols detected from the same species in this study. These different results were mostly due to the plant parts where the flavor compounds were extracted.

All 15 taxa of the common Chrysanthemum species contained two alcohols (phytol and borneol), which consisted of 32-92\% alcohols, depending on the species (Fig. 1). Phytol was one of the most abundant alcohol compounds in 6 taxa, with an average of $50 \%$ of the total alcohols. In particular, the phytol content in $C$. lineare was $67.6 \%$ of total alcohols. Phytol was identified as an antioxidant compound in Melittis melissophyllum (Maggi et al., 2010) and Eriobotrya japonica (Ham et al., 2012), and it was reported having high antimicrobial activity against Staphylococcus aureus (Inoue et al., 2005). With high phytol contents, these taxa may potentially be a great source for medicinal terpenic compounds.

Borneol was the most abundant alcohol compound in five $C$. zawadskii subspecies (ssp. acutilobum, ssp. acutilobum var. tenuisectum, ssp. acutilobum var. alpinum, ssp. lucidum, and ssp. coreanum) and C. indicum var. albescens, which had more than $11.5 \%$ of peak area (Table 4). Other four C. zawadskii species had less than $1.1 \%$ of peak area. In previous studies, Shunying et al. (2005) detected borneol (8.3-18.3\% of peak area) from $C$. indicum flower, however this study showed borneol was detected at $5.4 \%$ of peak area in the leaves of the same species, likely due to different plant parts where the flavor compounds were extracted. Borneol was reported to have an antimicrobial activity (Shunying et al., 2005).

All nine C. zawadskii species and C. makino contained

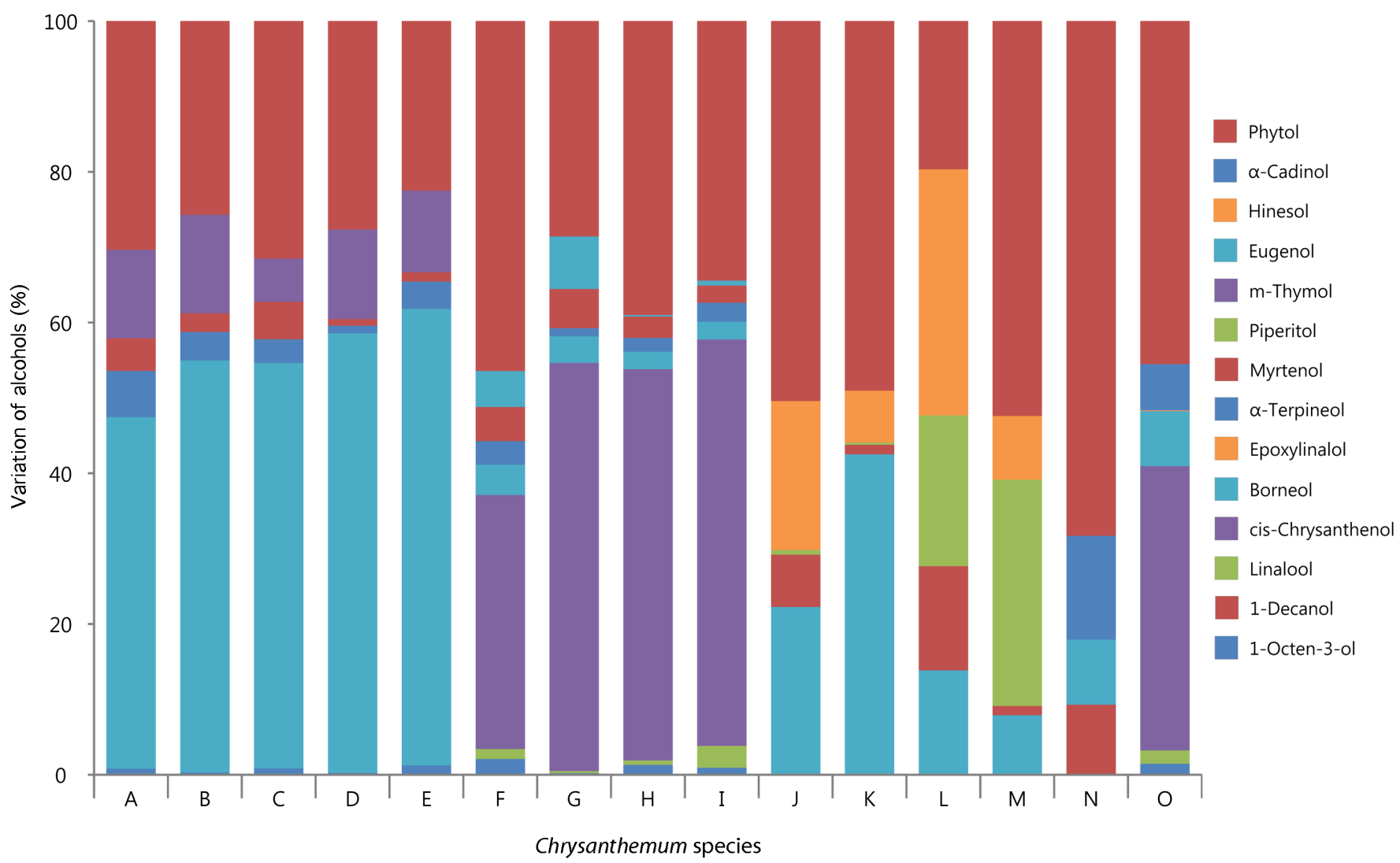

Fig. 1. Variation in the alcohols of volatile flavor compounds among 15 Korean native Chrysanthemum species in greenhouse of highland area. For species name, refer to Table 3. 
1-octen-3-ol. Interestingly, $m$-thymol was only detected in the five $C$. zawadskii subspecies with high borneol contents, whereas eugenol was only detected in the other four $C$. zawadskii subspecies.

In this study, large quantities of $m$-thymol were also seen in C. zawadskii ssp. lucidum (4.3\% of peak area) and C. zawadskii ssp. coreanum (3.4\% of peak area), indicating a potential as an ingredient for development of bactericidal drugs. Moreover, $m$-thymol has been reported to have a similar medicinal odor as phenol, with antiseptic and disinfectant qualities (Pirbalouti et al., 2013).

Linalool and cis-chrysanthenol were also detected from the four C. zawadskii subspecies and C. makinoi which contained low borneol. Linalool was often used as a raw incense in perfumes and cosmetics (Arctander, 1969), and had been reported to have strong inhibitory effect against 17 bacteria and 10 fungi (Pattnaik et al., 1997). cis-Chrysanthenol was not a common component in Chrysanthemum species as it had not been found in some $C$. zawadskii and $C$. indicum species (Hong, 2002; Shin et al., 2004; Woo et al., 2008). It has only been reported that $C$. indicum flowers (Jung, 2009) had a minor component of cis-chrysanthenol, and aerial part from $C$. boreale had cis-chrysanthenol as a major component (Hong, 2002). From the results of linalool and cis-chrysanthenol contents, there were two different subgroups within $C$. zawadskii subspecies, with different compositions of alcohols.

Piperitol and hinesol were only detected in three $C$. indicum subspecies and $C$. boreale. These two compounds might be good flavor compounds to identify $C$. indicum or $C$. boreale from other species. 1-decanol and $\alpha$-cadinol were detected only in $C$. lineare, indicating very specific flavor compounds for $C$. lineare.

\section{Ketones}

Ketones were the most abundant volatile flavor compounds in 7 taxa of Chrysanthemum species $(13.1-36.1 \%$ of peak area), including six C. zawadskii subspecies, and C. makinoi

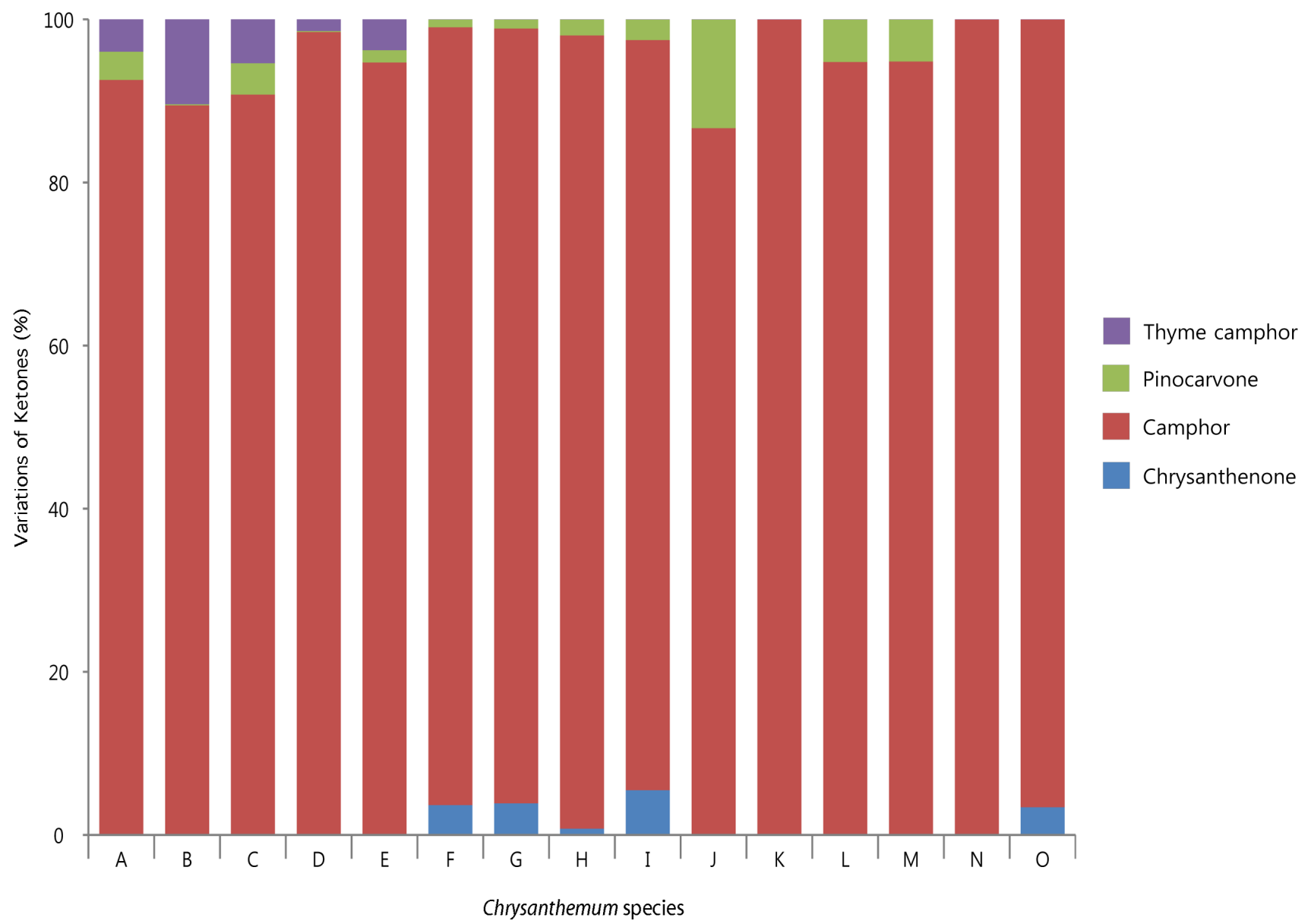

Fig. 2. Variation in the ketones of volatile flavor compounds among 15 taxa of Korean native Chrysanthemum species in greenhouse of highland area. For species name, refer to Table 3. 
(Table 4). Total of 4 ketones in Chrysanthemum species were camphor, pinocarvone, thyme camphor, and chrysanthenone. Camphor was the most common and the most abundant (86.7-100.0\% of total ketones) in these species (Fig. 2).

Camphor was detected in all 15 taxa of Chrysanthemum species investigated. It was the most abundant compound in most species. In particular, C. zawadskii ssp. latilobum and ssp. latilobum var. leiophyllum had high camphor contents with over $30 \%$ of peak area (Table 4 ). Camphor has been reported as an important substance for medicinal purposes (Arctander, 1969); it can alleviate itchiness or suppress cough or food poisoning bacteria (Jang et al., 2010), mostly due to its antimicrobial properties (Tzakou et al., 2001; Viljoen et al., 2003). Previously, several researchers (Chang and Kim, 2008) reported that the most predominant compounds of Chrysanthemum species were camphor, although there were some variations of camphor within Chrysanthemum species (Chang and Kim, 2008; Huang et al., 2001). These results correspond with the findings of previous research in Chrysanthemum species as containing high amounts of camphor.

Pinocarvone was also commonly detected in most Chrysanthemum species except for three taxa: $C$. indicum var. albescens, C. lineare, and C. makinoi. Pinocarvone, a similar compound to iso-pinocamphone, was reported to be contained in a large amount in Artemisia iwayomogi (Choe et al., 2004).

Interestingly, thyme camphor was detected only in five C. zawadskii subspecies with $m$-thymol (also had high borneol contents), and chrysanthenone was detected only in four C. zawadskii subspecies and C. makinoi, which had linalool and cis-chrysanthenol. As previously discussed, nine C. zawadskii subspecies could be divided into two groups not only by its alcohols, but also with ketones. Formerly, Chang and Kim (2009) identified 6 ketones $(15.3 \%$ of peak area) in C. indicum flower, which included camphor, filifolone, chrysanthenone, menthone, pinocarvone, and carvone.

Early researches revealed that chrysanthenone was not detected in Artemisia asictica or Matricaria camomilla in same Asteraceae, and was present only in $C$. boreale (Chang and Kim, 2009; Choi et al., 2006; Kim et al., 1994). However, this study revealed opposite results, suggesting that its content depedns on the plant organs such as leaf, flower or aerial part. Therefore, further research with plant partspecific comparative studies is needed.

\section{Hydrocarbons}

Hydrocarbons had the third most flavor compounds in Chrysanthemum species, which consisted of an average
$13.2 \%$ of peak area (Table 2). Among 19 hydrocarbons, $\alpha$-pinene, camphene, and germacrene-D were the only three compounds that were detected from all species (Table 4 and Fig. 3).

Interestingly, $\alpha$-thujene were detected only in four $C$. zawadskii subspecies such as ssp. naktongense, ssp. yezoense, ssp. latilobum, and ssp. latilobum var. leiophyllum, indicating specific flavor compounds in Chrysanthemum species. Jang et al. (2010) reported that $\alpha$-thujone had outstanding antibacterial, anticancer, anti-inflammatory, anti-ulcer, and anti-diabetic efficacies, and C. zawadskii subspecies may have potential ingredient for medicinal products.

Amount of $\alpha$-pinene content varied from $0.01 \%$ in $C$. indicum to $1.27 \%$ in C. zawadskii ssp. acutilobum, with an average of $0.7 \%$ of peak area (Table 4). Choi et al. (2006) noted that small amounts of $\alpha$-pinene were detected in $C$. boreale, which was consistent with this study $(0.2 \%$ of peak area). The $\alpha$-pinene was often used as a perfume ingredient (Arctander, 1969), and it was known to have anti-inflammatory effects (Jang et al., 2010). Since C. zawadskii ssp. acutilobum, C. zawadskii ssp. latilobum and $C$. indicum var. albescens were rich in $\alpha$-pinene (peak area $>1 \%$ ), they could be used as an ingredient for anti-inflammatory treatments. Although $\alpha$-pinene content of $C$. lineare was the highest (23.8\%), it only had four hydrocarbons since the percentage of total hydrocarbons of the species was relatively low $(0.79 \%$ of peak area).

Camphene was also detected in all 15 taxa of Chrysanthemum species, but its content is also dependent on the species. In particular, C. zawadskii ssp. acutilobum and C. indicum var. albescens contained high camphene content (2.04 and $3.57 \%$ of peak area, respectively), and consisted more than $18 \%$ of hydrocarbons. Woo et al. (2008) reported that camphene content of $C$. zawadskii was 5 times higher than the quantity in $C$. indicum. However, this study showed that $C$. indicum var. albescens contained high camphene (3.57\% of peak area), which was 21 folds of the amount detected in C. indicum $(0.17 \%$ of peak area). C. zawadskii ssp. latilobum appeared to contain a rather small amount of camphene $(0.06 \%$ of peak area), indicating that the camphene contents of $C$. zawadskii were also dependent on the subspecies. These results were different from previous report of Woo et al. (2008), and this is likely due to unclear distinction within C. zawadskii subspecies.

trans-Caryophyllene was detected in 14 taxa of Chrysanthemum species, except in C. lineare. Caryophyllene had been used in spices (Yeon et al., 2012), and it also was detected in Artemisia, Caryopteris, Cinnamonum, Citurs, Eucalyptus, Juniperus, Lavandula, Melissa, Menthe, Pinus, Salvia, Thymus, 


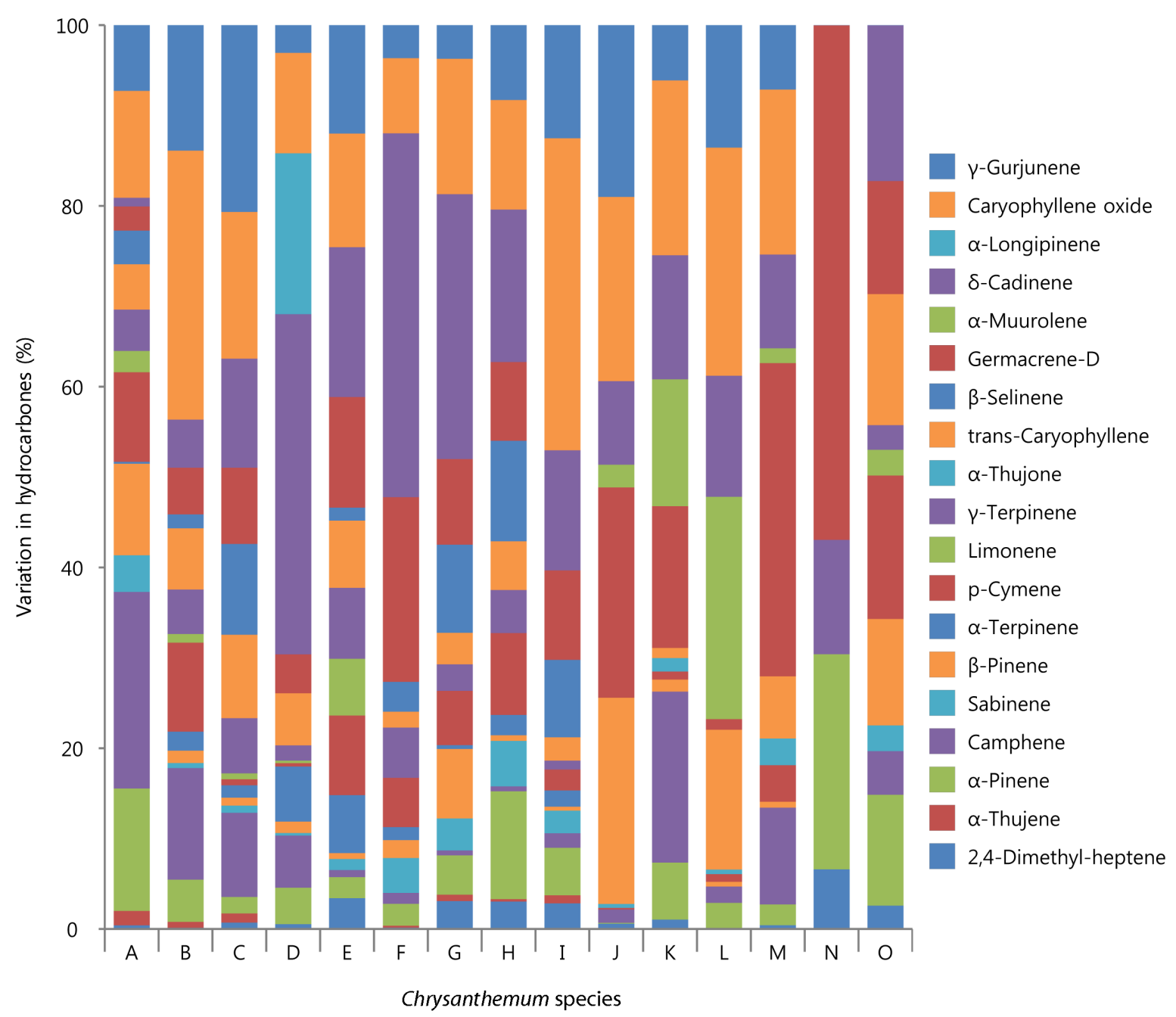

Fig. 3. Variation in the hydrocarbons of volatile flavor compounds among 15 taxa of Korean native Chrysanthemum species in greenhouse of highland area. For species name, refer to Table 3.

and Erigeron (Yu et al., 2008).

Germacrene-D was detected in all 15 taxa investigated. Its contents ranged from $0.18 \%$ in $C$. indicum var. acuta to $3.71 \%$ of peak area in C. zawadskii ssp. naktongense. Germacrene is a volatile hydrocarbon that exists in many plants, and it was known to exist as five isomers (A, B, $\mathrm{C}, \mathrm{D}$, and E). Germacrene-D was found to be an initial substance from the biosynthesis of sesquiterpene derivative (Ahn et al., 2002), and mainly known as a compound with high antibacterial and antioxidant effects (Rivero-Cruz et al., 2006). Woo et al. (2008) reported that C. zawadskii species contained higher germacrene-D than $C$. indicum species or C. morifolium. Hong (2002) also reported that the germacrene-D of $C$. boreale was $2.69 \%$ of peak area, and this study also showed the high germacrene-D content in C. zawadskii ssp. naktongense at $3.71 \%$ of peak area. Within nine C. zawadskii subspecies, germacrene-D contents also varied (0.25-3.71\% of peak area) depending on the subspecies. Among three $C$. indicum subspecies, two species had high content of germacrene-D $(2.67 \%$ and $2.96 \%$ of peak area for $C$. indicum and C. indicum var. albescens, respectively), and $C$. indicum var. acuta had the lowest germacrene-D content at $0.18 \%$ of peak area.

In this study, cadinene was detected in 14 taxa of Chrysanthemum species, except in $C$. lineare. Among all the hydrocarbons, $\delta$-cadinene content was the highest (16.6-40.3\% of total hydrocarbons) in 6 taxa, including C. zawadskii ssp. lucidum, ssp. coreanum, ssp. naktongense, ssp. yezoense, ssp. latilobum, and C. makinoi. This compound was reported to display bioactivities such as insecticidal, antipyretic, 
anti-inflammatory, anti-bacterial, and anti-cancer (Lee et al., 2012).

Caryophyllene oxide content was the highest among hydrocarbons in four taxa, including C. zawadskii ssp. acutilobum var. tenuisectum (29.8\%), C. zawadskii ssp. latilobum var. leiophyllum (34.5\%), C. indicum var. albescens (19.3\%), and C. indicum var. acuta (25.2\%) of total hydrocarbons. C. indicum had particularly high trans-caryophyllene $(22.8 \%)$ as well.

\section{Esters}

Although esters were relatively few (an average of 3.8\% of peak area) compared with other functional groups such as alcohols, ketones, and hydrocarbons, Esters were detected in all 15 taxa of Chrysanthemum species (Table 4 and Fig. 4).

Although 1,8-cineole was commonly detected in all 15 taxa of Chrysanthemum species, it was a relatively small amount among esters found in this study. Previous research indicated that 1,8-cineole was found in $C$. boreale and $C$. indicum, but not in Matricaria recutita, which was another genus in Asteraceae, suggesting it as an index compound for the species classification of Chrysanthemum (Chang and Kim, 2008; Choi et al., 2006). In particular, $C$. indicum var. acuta had the highest 1,8-cineole content at $3.50 \%$ of peak area. 1,8-cineole has been reported to have a suppressive effect on occurrences of mutations (Kim et al., 1992) with the recognition of actual chemical treatment effect on breast cancer in mice (Kubo et al., 1992), suggesting a possible potential ingredient for medicinal use.

trans-Sabinene hydrate and cis-sabiene hydrate were detected only in only nine C. zawadskii subspecies. transChrysanthenyl acetate and bornyl acetate were detected with a little amount depending on $C$. zawadskii subspecies. C. lineare contained bornyl acetate at $2.0 \%$ of peak area

Esters synthesized by short-chain acids and alcohols are a large group of flavor and fragrance compounds, which are used extensively in food, cosmetic, beverage, and pharmaceutical industries (Shu et al., 2011). Although one ester from $C$. indicum was detected in this study, four esters in same the species were identified as trans-sabinene hydrate, cis-sabinene hydrate, trans-chrysanthenyl acetate, and bornyl acetate (Chang and Kim, 2009)

\section{Acids}

Acids were detected in all $C$. indicum subspecies, $C$. boreale, C. lineare, and C. makinoi, but not in all C. zawadskii

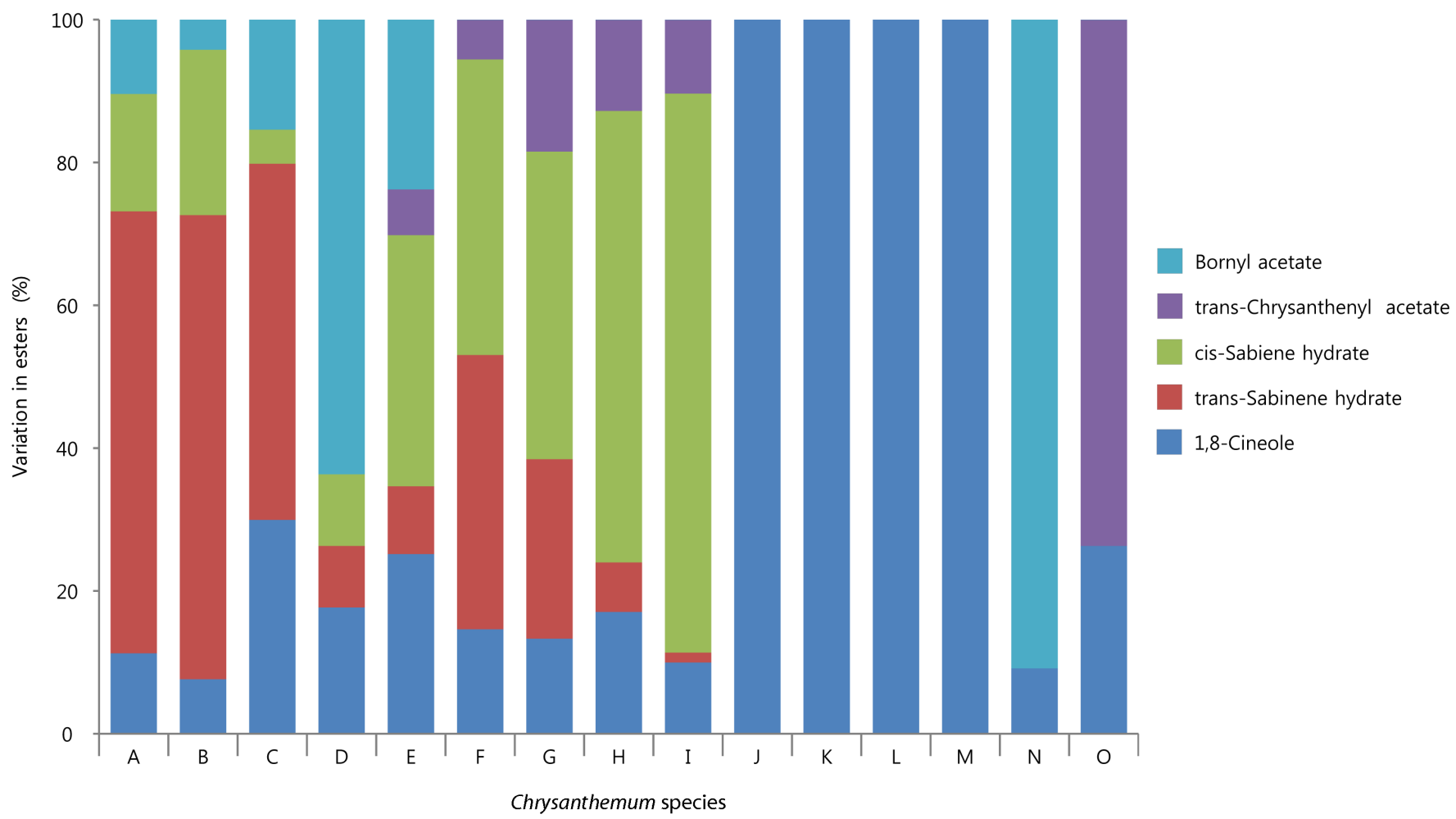

Fig. 4. Variation in the esters of volatile flavor compounds among 15 taxa of Korean native Chrysanthemum species in greenhouse of highland area. For species name, refer to Table 3. 
subspecies. Although acid content was low in most of Chrysanthemum species (average $2.1 \%$ of peak area), $C$. indicum had hexadecanic acid at 5.0\% of peak area and C. lineare had pentadecanoic acid at $10.9 \%$ of peak area (Table 4). In particular, only $C$. lineare contained pentadecanoic acid compound, whereas other species contained hexadecanoic acid. This specific compound was very unique to $C$. lineare, and this species had also unique morphological characteristics with different leaf and seed shapes from the other 14 taxa of Chrysanthemum species (Kim et al., 2011). Woo et al. (2008) reported trace amount of acids was detected in $C$. indicum, but it was not detected in C. zawadskii. However, our results showed that four $C$. zawadskii subspecies contained hexadecanoic acid, indicating subspecies specific volatile flavor compound contents.

\section{Aldehyde}

Aldehyde was detected in all Chrysanthemum species except $C$. lineare, and only one type (trans-2-hexenal) was identified (Table 4). All the Chrysanthemum species contained very little amount of aldehyde (less than $0.3 \%$ of peak area). Choi et al. (2006) also reported that aldehyde content in Chrysanthemum was negligible, which was consistent with this study. Chang and Kim (2009) identified five aldehydes from $C$. indicum flowers with major compounds being 2hexanal, safranal, benzealdehyde, and phenylacetaldehyde. However, this study found only one aldehyde from $C$. indicum leaves, indicating difference in flavor compounds from different part of organ.

\section{Potential Usage of Korean Native Chrysanthemum Species}

This study was conducted to compare flavor compounds among 15 taxa of Korean native Chrysanthemum species by analyzing and comparing specific flavor compounds, which could be used as baseline data for the germplasms and potential ingredient for functional foods, medicines, and cosmetics. Korean native Chrysanthemum species showed a considerable variation in volatile flavor compounds in their leaves, and this study may provide a good indication of species specific potential usage for various applications.

Most $C$. zawadskii subspecies contained $\beta$-selinene, which is effective in simulating appetite and a treating nausea and diarrhea (Ravindran et al., 2004). Two C. zawadskii subspecies (ssp. acutilobum var. alpinum, and ssp. lucidum) had the most abundant borneol content (18.5-20.9\%), which was reported as a volatile compound with antimicrobial activity (Shunying et al., 2005). C. zawadskii ssp. latilobum and C. zawadskii ssp. latilobum var. leiophyllum contained over 30\% peak area of camphor, which was reported as a volatile compound with antimicrobial properties (Tzakou et al., 2001; Viljoen et al., 2003). In particular, C. zawadskii ssp. lucidum and C. zawadskii ssp. coreanum contained higher contents of $m$-thymol, which had antiseptic and antibacterial qualities. So, both species can be potentially used as a disinfectant in medical fields. Four C. zawadskii subspecies (ssp. naktongense, ssp. yezoense, ssp. latilobum, and ssp. latilobum var. leiophyllum) contained chrysanthenone, which may have additional use as raw material for cosmetics (Arctander, 1969).

C. indicum subspecies and C. boreale contained $\alpha$ thujone, which had outstanding anti-bacterial, anti-cancer, anti-inflammatory, anti-ulcer, and anti-diabetic efficacies (Jang et al., 2010). In particular, C. indicum var. albescens have a high utility in making perfumes, since it showed camphene content that was 21 times higher than $C$. indicum. Since $C$. indicum var. albescens also contains $\alpha$-pinene and offers anti-inflammatory effect, its value in cosmetics is expected to increase. $C$. indicum var. acuta contained a fairly high content of 1,8-cineole, which has an inhibitory effect on mutagenesis. Also, since 1,8-cineole has outstanding chemical effect (Kubo et al., 1992) in actual treatment of mice with breast cancer, this species may have a great potential as a medicinal plant material. $C$. lineare contained only pentadecanoic acid compound, whereas other species contained hexadecanoic acid. This species had also unique morphological characteristics from other 14 taxa of Chrysanthemum species. C. lineare was the most different species in hydrocarbon contents among the 15 taxa of Chrysanthemum species. It only contained three common compounds ( $\alpha$-pinene, camphene, and germacrene-D) and 2,4-dimethyl-heptene, with the least amount of hydrocarbons at $3.3 \%$ of the peak area.

Overall, Chrysanthemum species were found to have great potential in multiple applications such as cosmetic raw material or food and medicinal ingredients; especially, Korean native Chrysanthemum species had species-specific volatile flavor compounds in the leaves. Therefore, selection of the right species is important to extracting specific volatile compounds. Nevertheless, comparing volatile flavor compounds from different plant organs and finding proper processing methods to extract the useful volatile compound would be done in the future.

\section{Literature Cited}

Ahn, J.C., M.Y. Kim, O.T. Kim, K.S. Kim, S.H. Kim, S.H. Kim, and B. Hwang. 2002. Selection of the high yield capacity of 
Hwangchil lacquer and identification of aromatic components in essential oil of Dendropana $\times$ morbifera Lev. Kor. J. Med. Crop Sci. 10:126-131.

Arctander, S. 1969. Perfume and flavor chemicals (aroma chemicals). Allured Pub. Corp., Montclair, NJ, USA.

Bae, H.J., H.Y. Lee, and J.E. Paik. 2009. Physicochemical properties of sugar-snap cookies prepared with Chrysanthemum indicum Linne powder. Kor. J. Food Nutr. 22:570-576.

Bae, S.M. and S.C. Lee. 2008. Effect of hot-air drying temperature on volatile compounds in Chrysanthemum boreale M. flowers. Kor. J. Food Technol. 40:466-469.

Byun, Y.H., Y. Shim, S. Lim, S.H. Choi, N.H. Park, S.R. Moon, I.H. Koo, K.U. Lee, M.Y. Lee, H.J. Hong, H.S. Chung, Y.H. Lee, and S.W. Shin. 2006. Development of natural drugs against antibiotics-resistant bacteria from Artemisia and Chrysanthemum species in Korea and study on its active mechanism (1). Duksung Bull. Pharm. Sci. 17:13-21.

Cha, J.D., T.Y. Kim, W.H. Woo, K.Y. Chung, Y.O. You, K.J. Kim, and B.S. Kil. 2000. Effect of Chrysanthemum boreale essential oil to several microorganisms. Bull. Life Sci. Biotechnol. $7: 1-17$

Chang, K.M. and G.H. Kim. 2008. Comparative analysis of volatile flavor compounds from Zanthoxylum piperitum A.P. DC. J. Food Sci. Nutr. 13:33-39.

Chang, K.M. and G.H. Kim. 2009. Comparative chemical composition of domestic and imported Chrysanthemum indicum L. flower oils. Food Sci. Biotechnol. 18:1288-1292.

Choe, S.H., S.I. Im, E.Y. Jang, and Y.S. Jo. 2004. Volatile compounds of flower and seed of safflower. Kor. J. Food Sci. Technol. 36:196-201.

Choi, S.H., S.I. Im, and J.E. Bae. 2006. Analysis of aroma components flower tea of German chamomile and Chrysanthemum boreale Makino. Kor. J. Food Cookery Sci. 22:768-773.

Choi, Y.J. 1992. Korean ethonobotany. Academy Book, Seoul, Korea p. 53-58.

Ham, H.S., S.Y. Lee, D.W. Lee, J.H. Seong, H.S. Kim, D.S. Kim, and Y.G. Lee. 2012. Isolation and identification of antioxidant compounds of various solvents extracted from Eriobotrya japonica leaves. J. Life Sci. 22:1166-1172.

Hong, C.U. 2002. Essential oil composition of Chrysanthemum boreale and Chrysanthemum indicum. J. Kor. Soc. Agr. Chem. Biotechnol. 45:108-113.

Huang, Y.F., Y.M. Zhang, L. Tao, and H.Q. Wu. 2001. Chemical components of essential oil from flowers of Chrysanthemi indicum in Guangzhou. J. Instr. Anal. 20:40-41.

Indo, M. 1996. Synthetic perfume and materials-chemistry and products information. The Chemical Daily Co., Ltd., Tokyo, Japan.

Inoue, Y., T. Hada, A. Shiraishi, K. Hirose, H. Hamashina, and S. Kobayashi. 2005. Biphasic effects of geranylgeraniol, teprenone, and phytol on the growth of Staphylococcus aureus. Antimicrob. Agents Chemother. 49:1770-1774.
Jang, D.S., K.H. Park, J.R. Lee, T.J. Ha, Y.B. Park, S.H. Nam, and M.S. Yang. 1999. Antibacterial activities of sesquiterpene lactones isolated from Hemisteptia lyrata, Chrysanthemum zawadskii, and Chrysanthemum boreale. J. Kor. Soc. Agr. Chem. Biotechnol. 42:176-179.

Jang, M.R., J.E. Seo, J.H. Lee, M.S. Chung, and G.H. Kim. 2010. Antibacterial action against food-borne pathogens by the volatile flavor of essential oil from Chrysanthemum morifolium flower. Kor. J. Food Nutr. 23:154-161.

Jiang, H., F. Li, and S. Zeng. 2005. Capillary GC determination of B-elemene, camphor, and borneol in Chrysanthemum morifolium Ramat. Yaowu Fenzi Zazhi 25:508-511.

Jung, E.K. 2009. Chemical composition and antimicrobial activity of the essential oil of Chrysanthemum indicum against oral bacteria. J. Bacteriol. Virol. 39:61-69.

Kim, H.G., Y.E. Kim, J.R. Do, Y.C. Lee, and B.Y. Lee. 1995. Antioxidative activity and physiological activity of some Korean medicinal plants. Kor. J. Food Sci. Technol. 27:80-85.

Kim, J.H. 1997. Variation of concentration of terpenes in Chrysanthemum boreale. Kor. J. Ecol. 20:397-403.

Kim, J.O., Y.S. Kim, J.H. Lee, M.N. Kim, S.H. Rhee, S.H. Moon, and K.Y. Park. 1992. Antimutagenic effect of the major volatile compounds identified from mugwort (Artemisia asictica Nakai) leaves. J. Kor. Soc. Food Nutr. 21:308-313.

Kim, S.J., J.H. Nam, Y.I. Jin, S.Y. Hong, Y.H. Yoon, J.C. Jeong, and K.S. Kim. 2011. Classification of the genus Chrysanthemum in Korea by flower morphological characteristics. Kor. J. Hort. Sci. Technol. 29(Suppl. II):149. (Abstr.)

Kim, S.K., S.C. Lee, D.K. Kang, S.H. Chung, and S.D. Lee. 1998. Essential oil content and composition of aromatic constituents in some medicinal plant. Kor. J. Plant Res. 11:279-282.

Kim, Y.S., J.H. Lee, M.N. Kim, W.G. Lee, and J.O. Kim. 1994. Volatile flavor compounds from raw mugwort leaves and parched mugwort tea. J. Kor. Soc. Food Nutr. 23:261-267.

Ko, K.S. and E.S. Jeon. 2003. Ferns, fern-allis and seed bearing plants of Korea. Iljinsa, Seoul, Korea.

Kondjoyan, N. and J.L. Berdague 1996. A compilation of relative retention indices for the analysis of aromatic compounds. Laboratoire Flaveur, Clemont-Ferrand, Paris, France.

Kubo, I., H. Muroi, and M. Himejima. 1992. Antimicrobial activity of green tea flavor compounds and their combination effects. J. Agr. Food Chem. 40:245-248.

Lee, J.H., E.H. Kim, and J.H. Lee. 2008. Effect of Chrysanthemum zawadskii var. latilobum on the release of inflammatory mediators from LPS-stimulated mouse macrophages. J. Orient. Neuropsych. 19:209-221.

Lee, K.C, J.Y. Sa, M.H. Wang, and S.S. Han. 2012. Comparison of volatile aroma compounds between Synurus deltoids and Aster scaber leaves. J. Medi. Crop. Sci. 20:54-62.

Lee, S.H. and J.S. Lee. 2007. Production and characteristics of antidandruff compound from Chrysanthemum zawadskii. Kor. J. Microbiol. Biotechnol. 35:220-225. 
Lee, Y.N. 2006. New flora of Korea II. Kyohaksa, Seoul, Korea. Maggi, F, F. Papa, G. Cristalli, G. Sagratini, and S. Vittori. 2010. Characterization of the mushroom-like flavour of Melittis melissophyllum L. subsp. melissophyllum by headspace solidphase micro extraction (HS-SPME) coupled with gas chromatography (GC-FID) and gas chromatography-mass spectrometry (GC-MS). Food Chem. 123:983-992.

Matsuda, H., T. Morikawa, I. Toguchida, S. Harima, and M. Yoshikawa. 2002. Absolute stereo structures of two new flavanone glycosides and a phenylbutanoid glycoside from the flowers of Chrysanthemum indicum L.: Their inhibitory activities for rat lens aldose reductase medicinal flowers. VI. Chem. Pharm. Bull. 50:972-975.

Nam, S.H. and M.S. Yang. 1995. Antibacterial activities of extracts from Chrysanthemum boreale M. J. Agr. Food Chem. 38:269-272.

Nam, S.H., S.D. Choi, J.S. Choi, D.S. Jang, S.U. Choi, and M.S. Yang. 1997. Effects of sesquiterpene lactones isolated from Chrysanthemum boreale M. against sarcoma 180 implanted in ICR mice. J. Kor. Soc. Food Sci. Nutr. 26:144-147.

Park, G.S., M.Y. Choi, and J.G. Im. 2000. Comparative degree of gelatinization and retrogradation on Gamkugsulgie with added of Gamkug. J. East Asian Diet. Life 10:514-521.

Park, G.S. and Y.J. Shin. 1998. Mechanical characteristics and preferences of Gamkugsulgie-dduk by different addition of Chrysanthemum indicum L. J. East Asian Diet. Life 8:289-296.

Pattnaik, S., V.R. Subramanyam, M. Bapaji, and C.R. Kole. 1997. Antibacterial and antifungal activity of aromatic constituents of essential oils. Microbios 89:39-46.

Pirbalouti, A.G., M. Hashemi, and F.T. Ghahfarokhic. 2013. Essential oil and chemical compositions of wild and cultivated Thymus daenensis Celak and Thymus vulgaris L. Ind. Crops Prod. 48:43-48.

Ravindran, P.N., K.N. Babu, and M. Shylaja. 2004. Cinnamon and Cassia: The genus Cinnamonmum. Medicinal and Aromatic Plants-Industrial Profiles. CRC Press. New York, USA.

Rivero-Cruz, B., I. Rivero-Cruz, J.M. Rodriguez, C.M. CerdaGarcia-Rojas, and R. Mata. 2006. Qualitative and quantitative analysis of the active compounds of the essential oil from Brickellia veronicaefolia by nuclear magnetic resonance spectroscopy. J. Nat. Prod. 69:1172-1176.

Schultz, T.H., R.A. Flath, T.R. Mon, S.B. Eggling, and R. Teranishi. 1977. Isolation of volatile compounds from a model system. J. Agr. Food Chem. 25:446-449.

Shin, K.H., S.S. Kang, E.A. Seo, and S.W. Shin. 1995. Isolation of aldose reductase inhibitiors from the flowers of Chrysanthemum boreale. Arch. Pharm. Res. 18:65-68.
Shin, Y.J., J.R. Jeon, and G.S. Park. 2004. Physiochemical properties of Gamgug (Chrysanthemum indicum L.). J. Kor. Soc. Food Sci. Nutr. 33:146-151.

Shu, C., J. Cai, L. Huang, X. Zhu, and Z. Xu. 2011. Biocatalytic production of ethyl butyrate from butyric acid with immobilized Candida rugosa lipase on cotton cloth. J. Mol. Cat. B: Enzymatic 72:139-144.

Shunying, Z., Y. Yang, Y. Huaidong, Y. Yue, and Z. Guolin. 2005. Chemical composition and antimicrobial activity of the essential oils of Chrysanthemum indicum. J. Ethnopharmacol. 96:151-158.

Sung, J.Y., W.A. Joe, Y.H. Kim, S.J. Cheon, M.J. Jang, H.J. Choi, J.S. Lee, E.Y. Choi, H.S. Lee, D.I. Kim, J.O. Kim, B.J. An, and J.T. Lee. 2007. Study on the anti-oxidant activity of extracts from the Chrysanthemum indicum L. J. Appl. Orient. Med. 7:1-5.

Tzakou, O., D. Pitarokili, I.B. Chinou, and C. Harvala. 2001. Composition and antimicrobial activity of the essential oil of Salvia ringens. Planta Med. 67:81-83.

Viljoen, A., S. van Vuuren, E. Ernst, M. Klepser, B. Demirci, H. Baser, and B.E. van Wyk. 2003. Osmitopsis asteriscoides (Asteraceae)-the antimicrobial and essential oil composition of a Cape-Dutch remedy. J. Ethnopharmacol. 88:137-143.

Wang, Y.J. and X.W. Yang. 2006. GC-MS analysis of essential oil of the flower of the Chrysanthemum morifolium by the different processing methods. Zhongguo Zhong Yao Za Zhia 31:456-459.

Wang, Y.J., Q.S. Guo, X.W. Yang, W.B. Xu, and H.Y. Tao. 2008. Characterization of chemical components of essential oil from flowers of Chrysanthemum morifolium produced in Anhui province. China J. Chinese Materia Medica 33:2207-2211.

Woo, K.S., J.S. Yu., I.G. Hwang, Y.R. Lee, C.H. Lee, H.S. Yoon., J.S. Lee, and H.S. Jeong. 2008. Antioxidative activity of volatile compounds in flower of Chrysanthemum indicum, C. morifolium, and C. zawadskii. J. Kor. Soc. Food Sci. Nutr. 37:805-809.

Yeon, B.R., H.M. Cho, M.S. Yun, J.W. Jhoo, J.W. Jung, Y.H. Park, and S.M. Kim. 2012. Comparison of fragrance and chemical composition of essential oils in 'Gom-chewi' (Ligularia fischeri) and 'Handaeri gom-chewi' (Ligularia fischeri var. spicifoprmis). J. Kor. Soc. Food Sci. Nutr. 41:1758-1763.

Yoon, O.H. and J.S. Cho. 2007. Optimization of extraction conditions for hot water extracts from Chrysanthemum indicum L. by response surface methodology. Kor. J. Food Cookery Sci. 23:1-8.

Yu, J.M., Y.H. Park, and S.M. Kim. 2008. Floral volatile composition of daisy fleabean (Erigeron annuus L. Pers.). Kor. J. Weed Sci. 28:274-278. 